\title{
Co-housing childhoods: parents' mediation of urban risk through participation in intentional communities
}

\author{
Roza Tchoukaleyska \\ Department of Geography, University of Sheffield, Sheffield, S10 2TN, UK
}

\begin{abstract}
Co-housing is a form of intentional community that encourages shared living and sees members jointly build and develop urban housing projects. Through an emphasis on traffic-free developments and reference to strong community sentiment, co-housing is construed by parents as providing a safer and more desirable location for raising children. Drawing on fieldwork in two Canadian co-housing developments, this paper demonstrates how parents are able to mediate risks associated with traffic, bullies, and strangers.
\end{abstract}

Keywords: co-housing; safety; urban village; community; Canada.

A growing body of literature in geography has examined urban and rural childhoods in western society. Considering the UK context, James and James (2004) suggest increasing ambivalence over the meaning of childhood and the social and political role of children and youth. Contrasting visions of children as 'angels' and 'devils', Valentine (1996) argues, position youth as at once innocent and in need of adult guidance and protection, and a social danger contributing to crime and public degeneration. Fears for the safety of children - from traffic (Nayak 2003, Mitchell et al. 2007), bullies and gangs (Valentine 1997a, Lucas 1998), and stranger-danger (Veitch et al. 2006, Holloway and Valentine 2000) - have rendered public space a contested terrain not always suitable for, or accessible to, youth (Watt and Stenson 1998, Matthews et al. 2000, Castonguay and Jutras 2009). The 'moral panic' over childhood, and the association of safety threats with public spaces, has put increasing pressure on parents to restrict their children's outdoor activities. The ability of children to explore their surroundings without adult supervision has decreased (Matthews 1987, Valentine and McKendrick 1997), as have the opportunities for children to walk to school on their own (Veitch et al. 2006). Play has seemingly 
Pre-print version

become more indoors, with children occupied by home-based activities, TV and computer games (Oswell 1998, Christensen and O'Brien 2003), and indoor playgrounds and organized athletic and cultural activities (McKendrick et al 2000). In contrast to the urban setting, the countryside is in some instances viewed as a more appropriate environment for youth: idealized as space where children can freely explore and find companions, rural areas are conceptualized as removed from the dangers of city life. In the 'pure spaces' of nature (Jones 2000, p.34), children can be allowed to play outdoors, recapturing an idyllic youth that includes adventure, exploration, the building of dens, and free play (Hallden 2003, Jones 1997). In the countryside the adult and child spheres could be safely separated, since public spaces - the mall, the street, the train station - are removed to the nearest village, and with them the dangers of traffic, strangers, and teen bullies. Although rural children are often as involved in formal sports and cultural activities as urban children (Mattisson 2002) and rarely use nature for the sort of creative games adults envision (Matthews et al. 2000), the sense of community and kinship associated with countryside living is constructed by parents as desirable (Valentine 1997b).

Yet a rural escape is not the only approach to dealing with the perceived difficulties of urban childhoods: the creation of alternative living communities in both urban and rural spaces present another option. In a study of children's agency in two Welsh communities Maxey (2004) finds that younger people have significant autonomy and decision making ability with respect to socio-cultural freedoms: exploring the surroundings of each community without adult supervision, travelling to see friends on their own, and making decisions on schooling with the support of their parents. In another study based in Wales, Kraftl (2006) traces the development and construction of a Steiner alternative school. Suggesting that the built form of the 
Pre-print version

school is a reflection of the group's visions of an idealized childhood - with its smoothly curved walls, warm colours, homely environment, and emphasis on learning through experience - Kraftl (2006; see also 2009) argues for the importance of the physical environment in defining the experiences of younger people. While often neglected by geographers, the presence of children in intentional communities provides a unique avenue for understanding other mechanisms used by parents to mediate some of the risks associated with modern urban living.

This paper will draw on research in two Canadian co-housing developments, contributing a North American example to existing studies of children in intentional communities. A form of alternative living that encourages shared spaces, co-housing sees members jointly built and develop urban housing projects with a particular emphasis on creating a village-like environment in the city. Through an emphasis on traffic-free developments and reference to strong community sentiment, co-housing suggests a sense of safety associated with traditional rural communities, yet it is often set within large towns and cities. It allows parents to reconcile the needs of their children with their own needs for access to city services and employment, and reestablishes the urban neighbourhood as a desirable location for children. Drawing on interviews conducted with parents, this paper explores the ways in which families mobilize ideals of community and safety by reference to the co-housing model.

\section{Cohousing: Village in the City}

Initiated as an alternative to suburban living, the co-housing movement was first developed by young professionals and families seeking a new urban living model in 1960s Denmark (Fromm 1991). The movement has its origins in the communitarian and collective housing models of Denmark and Northern Europe, with 
Pre-print version

the particular aim of mobilizing strong social networks in support of working parents and families (Williams 2005). While borrowing from older communitarian models and ideals - with communal resources, meals, childcare and living space - co-housing simultaneously seeks integration with mainstream society. Following Meijering et al (2006) co-housing can be understood as a 'practical community', meaning that members aim to create a new urban community within mainstream society rather then withdraw to the countryside or establish an alternative utopian model (Halfacree 2006). Co-housing members retain a degree of privacy and independence through individual home ownership and household management (McCamant and Durrett 1989), maintain jobs in the city, register their children in state schools, and continue to participate in popular cultural, social and sports activities. In contrast to the goals of other types of intentional communities, an alternative education for children does not necessarily figure into the co-housing model. The emphasis is overwhelmingly on an improvement in the physical and social condition of living environments, with education left for each family to determine for their children.

Ranging in size from a few families - smaller co-housing developments are characteristic of North America - to upwards of 100 households in Denmark ${ }^{\mathrm{i}}$ (Meltzer 1999), co-housing sees single-family homes or apartments clustered around a large common house and gardens. Communities are designed to encourage pedestrian usage - with cars and parking lots on the periphery of the estate - and multiple pathways, patios, and playgrounds at their centre. Family homes, at least in the Danish model (Fromm 1991, p.9), are smaller than neighbouring houses, with much of the living space transferred to the common house. The common house, in turn, provides room for community dinners, play areas for children, meeting rooms, and in some instances music and game rooms, and storage for shared garden and household implements. 
Pre-print version

The co-housing design, Fromm (1991) suggests, is intended to mediate the social and physical isolation of suburban living by encouraging stronger community bonds, mutual interdependence, friendship, a stable environment for children, and support networks for working parents.

Although co-housing takes a variety of forms, the leading proponents of the movement in North America, Kathy McCamant and Charles Durrett (1989), have identified four key characteristics common to most developments: accessible social spaces; common meals; participatory decision making; and self-management. The original 'Danish model,' McCamant and Durrett (1989) suggest in their influential book Cohousing: A Contemporary Approach to Housing Ourselves, has an architectural layout that incorporates features such as pedestrian pathways, porches, gardens and meeting areas. In particular, pathways and play spaces are positioned so as to encourage 'accidental' meetings by neighbours: kitchens facing the common green and path, a main entry point into the development, and easy access to shared facilities. A common house and shared meals are also noted as characteristic of cohousing and key to the establishment of a community spirit. Co-housing, McCamant and Durrett (1989) further note, is developed through a participatory process where residents are jointly involved in the organization, planning, and design of their community: from the purchase of land, to the hiring of architects and overseeing of the project, residents determine the physical layout of their environment and the main community tenets and ideals. Finally, co-housing is based on resident selfmanagement with members using a consensus process and study-groups to make decisions on finance, to set guidelines for the admittance of new members, and to address common concerns. The co-housing model effectively attempts to manage the 
social and physical living environment of members with the hope of providing an integrated, supportive community.

A predominantly urban movement, co-housing communities number in the hundreds in Denmark where government financial and social programs have been introduced to aid with loans, mortgages, and building construction programs (Meltzer 2001). Projects in Denmark and Western Europe are aimed at a variety of social groups. Several co-housing developments geared towards the specific needs of retirees are noted in Scandinavia, along with more traditional designs for the requirements of families (Meltzer 2001). McCamant and Durrett claim their 1989 book as North America's first introduction to the concept co-housing - earlier works on the topics being available in Europe and not in English - with a number of developments subsequently emerging in California, British Columbia, and North Carolina. McCamant and Durrett (1989) are widely cited in literature on co-housing (Meltzer 1999, Fromm 1991, Canadian Co-housing Network), as well as by many cohousing members interviewed as part of this project. Communities in North America typically have a smaller number of members (Meltzer 1999, Co-housing Association of the United States), and more limited communal activities with shared meals once or twice a week, compared to the nightly community meal in the Danish model (Fromm 1991). Within Canada, the Canadian Co-housing Network website lists close to 20 communities as either in development or functioning. Most of them are concentrated in Western Canada, with a smaller number in Central Canada.

The development of co-housing, argues Meltzer (1995), is a response to the degeneration of urban communities in the late twentieth-century society. As Fromm notes in his examination of co-housing culture, "the Dutch [co-housing] groups questioned not only the isolation of the one-family home, but also the isolation 
brought about by the nuclear family structure"(1991, p.48). As McCamant and

Durrett suggest, modern family life has become morally and physically draining:

[we] would come home from work exhausted and hungry, only to find the refrigerator empty. Between our jobs and housekeeping, where would we find the time to spend with our kids?...Most young parents we knew seemed to spend most of their time shuttling their children to and from daycare and playmates' homes, leaving little opportunity for anything else (1989:9).

Co-housing, McCamant and Durrett argue, is a welcome alternative which reestablishes "many of the advantages of traditional villages within the context of late twentieth-century life" (1989, p.7). Through self-selecting communities, members are able to form stable and lasting familial support networks, to provide children with safe spaces to play, to reduce the stress of arranging meals and managing household tasks individually, and most of all, to be certain of the reliability of their friends and neighbours. Modern single-family housing is altered to meet the needs of urban dualincome families, and suburban car-culture is rejected in favour of pedestrian pathways, and reliance on car-sharing and public transit.

Children are at the centre of the co-housing 'village in the city'. McCamant and Durrett's (1989) influential introduction to co-housing makes ample use of family images and careful references to the particular benefits this model of living provides to children. Through a series of vignettes and photographs of Danish co-housing groups, McCamant and Durrett implore their readers to imagine scenarios such as the following:

It's five o'clock in the evening, and Anne is glad the work day is over. As she pulls into her driveway, she begins to unwind at last. Some neighbourhood kids dart through the trees, playing a mysterious game at the edge of the gravel parking lot. Her daughter yells, 'Hi Mom!' as she runs by with three other children. Instead of frantically trying to put together a nutritious dinner, Anne can relax now, spend some time with her children, and then eat with her family in the common house $(1989$, p.11). 
Pre-print version

In another well-circulated guide to co-housing communities, Diane Leafe Christiansen suggests, that a key tenet of co-housing is to "create a culture which nourishes our children" (2003, p.xviii). Children figure prominently in images of Fromm's (1991) guide as well, with photos of kids playing, swimming, talking with adults, and taking part in community activities. The images are idyllic. Along with McCamant and Durrett's (1989) evocative vignettes, the recurrence of child-centred photos place youth and families at the centre of the co-housing model. Co-housing, these guides suggest, makes particular allowance for the needs of children: interior playrooms, teenagers' 'jam room', playgrounds and car-free zones, and reliable adult supervision. The sense of community, Fromm (1991) and Christiansen's (2003) guides implicitly suggest, is derived from a joint need to assist working parents and provide support through the reduction of household and familial tasks. Co-housing parents, Thorleifsdottir (2008) notes with respect to communities in North Carolina, feel their children are safer within the pedestrian and well supervised spaces of their developments.

The co-housing premise is captivating, and the research presented in this paper is inspired by a desire to better understand the experience of parents within this particular model of an intentional community. Especially in the context of increasing fears for the safety of children in urban environments (Valentine 1997a), co-housing appears to provide a novel solution. As a 'village in the city' - following McCamant and Durrett (1989) - co-housing suggests an urban childhood idyll, and a mutualsupport setting for working parents. Reliable community is presented as the panacea for urban anxieties, and is cultivated through careful architectural design and active consensus-building. 
Pre-print version

\section{Methodology}

This research is focused on two co-housing communities in Central Canada ${ }^{\mathrm{ii}}$. The participants were selected through the Canadian Co-housing Network, an association providing a comprehensive online database of Canadian co-housing developments. Amongst several communities listed for Central Canada, two were chosen as case studies. The selection of case studies was determined by the possibility to reach each community by public transport, and by members' agreement to participate in the project. Both communities - Phase II and Dover - are based in large towns. While Dover was still in the development stages with new members being accepted, Phase II had functioned as a community for a number of years and was in the process of expanding.

Interviews with Phase II members took place in the co-housing community, where three family interviews were arranged: In one instance both parents were present, in the others only the mothers were available during that phase of the day. Two of the families had children living at home, and one had adult children, who had spent periods of various lengths in the community. I was also invited to take part in the Phase II Sunday night community dinner, and chatted informally with several cohousing members and neighbours. As Dover was still in the conceptual stage, a group interview with five Dover members was held at the home of one of the main organizers. Amongst the interviewees were both couples, and single members with grown children. Subsequently, two further interviews were held with Dover members, in both instances families with young children who were unable to attend the group interviews. These interviews took place in the suburban homes of participants, and included both parents. The semi-structured interviews lasted approximately one hour, 
Pre-print version

and all participants were adults over the age of 18 . The limited nature of the project and ethical board considerations did not make allowance for interviews with children.

\section{Children in Cohousing Communities: Two Case Studies}

Both Phase II and Dover are urban-based co-housing communities in Central Canada. Although Dover was still in the conceptual stage, members had already chosen an architect, and at the time of research were actively searching for suitable land, or for a building located in a downtown neighbourhood, which could be purchased and refurbished according to their needs. Dover had eight regular members, comprising both families and individuals, and four associate members who were participating in the development process, but had yet to make a full financial commitment. Dover members were aiming for a 20-25 unit co-housing development of either stacked town-homes or apartments, with a large common house and gardens. Through a consensus-building process and task-specific working-groups, they had developed a community design criteria to guide their architect, and to inform prospective members of the envisioned community environment. Dover were aiming for a high-density development with outdoor parking and a range of units: from studio apartments (550 square feet), to 4-bedroom units (1500 square feet), and a number of wheel-chair accessible units. Ideally, Dover members would like their community to cluster around a courtyard with pedestrian paths, gardens, trees, planting boxes, a children's play area with outdoor climbing gear, picnic benches and an outdoor BBQ. The common house would function as an entrance point into the community, and a meeting area for residents. The common-house design comprised a children's playroom, a dining room which could be rented out for neighbourhood events, and a lounge with a fire place that would be used only by residents. The building would 
Pre-print version

ideally have a brick exterior that would blend in with older homes in the area. While the cost for each unit was yet to be determined, members intended to maintain competitive pricing with regard to comparable city-centre housing and condominiums, so as to attract new members.

Dover co-housing members meet every two weeks for a potluck dinner and group discussion. Respect, honesty and mutual support are the central values for the community, and prospective members are asked to accept the group's vision statement and building design criteria. In the past, the group has worked with a consultant to help with the planning process, and to mediate contentious points. All Dover members have university degrees, with several holding postgraduate qualifications. Phase II members have similar educational qualifications: All interviewed individuals held an undergraduate degree, and several members had Masters degrees. All interviewees at both communities were employed, with most indicating they worked close to the city-centres.

Completed in 1997, Phase II was located close to the city-centre and had six town-home units with a seventh unit nearing completion. A long-awaited community house was also under construction. Phase II was described by residents as an 'urban reclamation project' that involved the restoration of two side-by-side townhouse properties originally built in the 1880 's. When the buildings were bought, the two three-door units were jointly valued at just over half-a million Canadian dollars. A Phase II resident described the neighbourhood at the time of purchase as "this little backwater with a lot of workers' houses". With the added value of renovations and changes in the real estate market, the property is now worth more than triple its original value ${ }^{\mathrm{iii}}$. The neighbourhood, Phase II residents indicated during the community meal, has been revitalized over the years with health food stores, 
Pre-print version

restaurants, and cafes locating on the main commercial road nearby. Ongoing construction has created the new, seventh Phase II unit in the space between the two townhouse blocks - what had previously been a 4-car driveway. The new common house was to be located in the basement of the new addition, and it was going to be wheelchair accessible. The Phase II back yard was the community 'green space.' It was created by co-housing residents removing the wooden fences dividing the original individual townhouse properties. The community green had a tree house, shed, landscaped garden, and shrubs. Each townhouse had a deck which extended into the back garden, and was considered a private space by residents: the deck was used by household members only, while the picnic bench and patio furniture in the garden provided spaces for residents to meet and chat outside. Until 2004, Phase II members were tenants-in-common. In 2005 they incorporated as a condominium, with each household owning their individual townhouse and a portion of the common house and garden. A resident noted that families owned their units just 'past the wall paint', and could not make structural changes or repairs without general agreement. As a jointlypurchased property, all members contributed in varying degrees to the down-payment. Some provided more funds towards the initial purchase, while others are contributing more towards the mortgage payments.

Phase II had common dinners twice a week, on Wednesday and Sunday nights. The Wednesday night dinner was attended by Phase II residents only, with members taking turns preparing the meal and cleaning up afterwards. The Sunday night meal included 3 neighbouring households in the rotation. Wednesday and Sunday dinners were held in the same place: two adjoining homes at the north end of the community, which have larger kitchens and backrooms. Usually, residents prepare vegetarian meals, and provide sugar-free desserts. Both children and adults eat 
Pre-print version

together, with the kids later retreating to the basement for movies and quiet games. Shared dinners were to shift to the common house once it was completed.

\section{Designing co-housing for children}

Children have a unique place in the Phase II and Dover co-housing communities. The Dover community covenant - a document outlining the main ideals and goals of the group - holds the well-being of children as a core value: "our community offers an emotionally and physically safe place for everyone, but especially children and other vulnerable people"(Dover covenant). The covenant describes that sense of safety as "protecting those who are vulnerable from emotional and physical harm" and ensuring space for self-expression (Dover covenant). The Dover community documents were produced through a series of member consultation, occasionally with the help of an outside community consultant. As several members have children - or are expecting children - support for families is seen an important aspect of Dover's development and purpose. As the Dover community was still in the planning stages, the translation of these ideals into everyday practice is still being defined. Similarly, the founding documents of Phase II include a commitment to "a shared responsibility for children (without denying the parents' primary role)" (Phase II vision documents). Through these guiding documents, the co-housing community as a whole becomes responsible for the well being of the youngest members.

While both communities indicate a desire to provide children with a positive, family-oriented and safe environment, youth themselves are rarely involved in the planning process. Dover members argue that children within the community are too young - toddlers, pre-schoolers, and elementary school - to meaningfully contribute to the planning process. Recalling the co-housing planning process, Phase II residents 
also note that children were not directly involved in determining the layout and function of the community. In part, again, because many of the community's children were seen as too young, but also because planning sessions took place in the evenings and centred on financial and real estate consideration. Both Phase II and Dover members are conscious of the disconnect between a desire to build community for the benefit of children and the seeming inability to involved youth in the planning phases of each project. Yet members of both groups indicate that community design takes into consideration the needs of children by providing safe play spaces.

The Dover architectural plans and the already existing Phase II community have controlled entry and access. Dover envisions inward facing houses, with entries to individual units and kitchen and living room windows facing the common green rather than street-side. With children's play areas built into the development's structure - in the form of a play room and a yard - the spaces children can occupy are more easily identified and supervised. The large common yard of Phase II is accessed through the individual houses of members, and visible to the kitchens and living rooms of the homes. Strangers are quickly spotted and children's play, although not directly managed, is overseen. There is at once freedom to roam and explore, and safety in the knowledge that trustworthy neighbours are keeping an eye on the kids. Although the limits of common spaces are static children are permitted to modify their play environments, through the construction of dens and play houses, borrowing of toys, relocation of play tools from one part of the common space to others, and the liberty to roam the property uninhibited. For Dover and Phase II parents the increased sense of security associated with co-housing is seen as beneficial to children; the inability to directly speak each group's children hampers any understanding of how youth themselves understand these processes. 


\section{Mobilizing community to mediate urban risks}

Discussing the reasons behind the selection of co-housing for their families, parents indicate that this enhanced sense of community was important in their decision to become members:

I think we've decided as we've decided, you know, first it was more that we were going to live in community. But as we've made the decision to have children of our own we've felt that this [co-housing] was an absolute necessity. This is the way we want to raise our kids. (Dover member, expecting).

(Phase II resident): Community is to me, is, about, I guess having a level of comfort and trust in people....And it's also very much about, about the children and, you know, having some sense of connection to the kids and seeing their milestones, and, you know, feeling connected in one way.

(Interviewer): Were your children a factor in deciding to start Phase II?

(Phase II resident): Absolutely. Yeah, I mean, [my husband] and I were founders of the concept of this community and it was before we had children. We started, you know, and one of the things that we agreed and that I, I sort of said, you know, before we have kids I'd like to know that we're on this path because I think it would make life a lot easier and more enjoyable for everybody. (Phase II resident, two children ages 6 and 11).

The concept of community is actively mobilized to provide support to parents, and to counter some of the difficulties associated with city-centre living. It inspires a level of trust and engagement that, this parent of grown children argues, was unavailable in her suburban family home:

I didn't have any help or interactive contact with neighbours [in the suburbs]..... There was just absolutely lack of community. It wasn't there to be had, but even if you tried to create it, there was no resources to create community with. (Dover member, grown children)

Through an emphasis on physical proximity and members' interdependence, cohousing becomes a safe-haven of sorts. The space of the city is transformed, the shared gardens, common house and meals allow for a unique form of familiarity:

I would say all the kids in the community trust all the adults in the community to the point where, you know, if they needed help they would know to come to anyone of us....It's just a very, it's just an understood thing. Anyone of them can ask for help. (Phase II resident, grown children) 
Our kids, you know, have said it's like there's other parents really. And also the kids, too, they consider [other co-housing members] part of their extended family. (Phase II resident, father, three children 16-23)

Rather than being depicted as threatening strangers, surrounding neighbours become kin. However, the spaces outside the co-housing development are perceived to be less well suited to the needs of children. When asked what dangers children could encounter in the city, parents responded:

Yeah, well like you know, traffic in the area where we live [while Dover is under development], and we, we're right next to a church where there's a lot of panhandlers around there, and a couple of streets over from [that street], so there's just a lot of people. (Dover member, expecting)

(Phase II resident): You know, when I was growing up I mean, we had a lot of fluidity, we could go out. But I get the sense now that, you know, that kids are much more constrained and there's, there's more fear around about, you know, about letting them kind of explore boundaries in an urban setting anyways, so.

(Interviewer): What sort of fear?

(Phase II resident): Fears that of being, you know, kidnapped or molested or whatever. (Phase II resident, two children ages 6 and 11).

As Valentine (1997b) has indicated, parents' anxieties about the city are linked to the perceived inability of children to safely negotiate public space. For Dover and Phase II parents, public space can be insecure and difficult to manage. The panhandlers who meet close to the church are perceived as threatening, making that place unusable for youth. The intrusion of 'unsavoury' characters into potential play areas has limited kids' outdoor activities. Living in a co-housing group, parents are able to overcome some of the concerns surrounding both city dangers, and the apparently negative aspects of modern childhoods. With fellow members keeping watch over the enclosed common garden, children can play safely. Phase II is a block away from a large Catholic high school, and many students pass the community on their way to and from classes. Although concerned with the potential for bullying by older children, 
parents felt that through their participation in co-housing, their children's safety would became a concern for all adults:

(Phase II resident, father): [This] is a fairly safe city and we live in a fairly safe part of the city. But you know having said that there's always the possibility of people coming here [Phase II neighbourhood]. So in terms of what dangers are, you know, abduction or. But I think it would be hard just because kids have many eyes on them.

(Phase II resident, mother): And you know, if there was a situation that they felt uncomfortable there are lot of, lots of people that they can go to. There are lots of door that they can go to for support. And you know, bullies, again you know, like if there was somebody that was bugging them chasing them, or whatever, you know, there's 10 doors they go to any of those doors and say you know I need help. (Phase II residents, three children ages 16-23)

For Dover members, who have yet to become co-housing residents, the intentional community design holds the potential of alleviating some of their concerns about the structure of children's play. When queried on the changes they envision in their children's lives through a move to an intentional community, Dover members suggested that co-housing would allow more play-flexibility and an opportunity to unstructure the nature of their kids' leisure activities:

It's [playtime] more difficult when you have to work harder at coordinating it. I mean, may be, we're part of a church and there's lots of kids there. But you've gotta schedule, and you have to arrange play dates. And I would just like for my kids to be able to run out the door and see whoever's there. And just have these really natural, easy, spontaneous interactions (Dover member, expecting)

That freedom to be able to tell your mom, 'OK mom I'm going outside I'm gonna play with my friends' and your parents they are not worried, they say OK you're not allowed to go further than this street. And you know that within that area you're free to explore, your parents are not worried because they know the people around. But yeah, I don't think children nowadays have that kind of freedom, to just roam around. (Dover member, single)

We live downtown right now and I wouldn't send, if we had a child, I would not send the child out the door to go play. Because it's just, there's all kinds of characters. I mean it's a great place to live and we love it there, but the child would have to be closely supervised. (Dover member, completing international adoption)

Co-housing, then, provides reliable friends for children, and a sense of parental security through the removal of street-strangers. Intentional community, through its 
Pre-print version

enclosed design and emphasis on tight-knit neighbourhoods, serves to mediate some of the risks parents associate with urban life.

\section{Village in the city}

As Diane Leafe Christiansen indicates in her guide to developments, a key tenet of co-housing is the creation of a community reminiscent of "our grandparents generation" (2003, p.xvii). Dover and Phase II members consciously mobilize this sentiment with reference to the phrase 'it takes a village to raise a child,' with the cohousing development cast as the village:

(Dover member, 1): I remember you saying that it takes a whole village to raise a child.

(Dover member, 2): Well yes, we're gonna create our village.

(Dover member, 3): Otherwise being trapped in suburbia is very hard and very lonely. (Dover members, mixture of parents and members without children)

The kids have, have a sense of comfort with other adults and, you know, its as simple as the old saying it takes a village to raise a child, you know. (Phase II resident, two children ages 6 and 11)

Sam...had seen that Jane was stressed, and so had just taken [her] two year old and walked away, you know.... So he was just going around and, and you know with her and having her peek into people's windows, you know. So I think it was that kind of belief that it takes a village to raise a child, kind of belief. (Phase II resident, grown children, describing how a co-housing member helped a Phase II parent when she was overwhelmed).

Community, this mother of two young children indicates, is knowing that support is available, and that your fellow 'village' members are keenly interested in your wellbeing:

[Community is] a sense of security and a sense of being cared for. And, yeah, that's it really. You know, that there, that there are people who love you, who care about you, who are, ah, you know, really interested in helping you to flourish. Cause I think that there's that here too, you know, that, that we really, we really have each other's best interests at heart. And, you know, so it's a pretty non-competitive, you know, secure environment in, that sense. You know, it's, it's a place to come home to, just where you can just relax and not have to worry about stuff. (Phase II resident, two children ages 6 and 11) 
The desire to be surrounded by a stable, village-like urban community is not always satisfied by regular city housing. As this co-housing resident indicates, it is necessary to actively seek out the conditions and fellow members who could contribute to making community a reality:

The problem with good neighbourhoods is that they're a bit more hit and miss, you know. You're going to end up in one not so, you know. I think we all wanted to make sure we did end up in one [good neighbourhood] (Phase II resident, two children).

A good neighbourhood, or an 'urban village', encourage a re-consideration of social relations, as this co-housing parent indicates:

I really wanted to have my children have the opportunity to have friends, and I mean like school segregates children by age....And I really wanted my kids to have the opportunity to have friends that were you know infants and friends that were retired. (Phase II resident, mother, three children ages 1623).

Within a rural setting Matthews et al (2000, p.151) find that "in their day-to-day transactions, too many rural children felt observed and censored, seldom able to find autonomous social space away from the adult gaze". Co-housing safety is built on adult supervision. Parents indicate that they feeling greater security because "chances are there'll be an adult around"(Phase II resident, mother, grown children). Pedestrian communities and enclosed common greens ensure distance from traffic, thought at the same time they discourage exploration of the neighbourhood more broadly and concentrate play within specific non-public spaces. The inability of children to play autonomously and explore their surroundings unsupervised raises questions about children's agency in the urban environment (Zeiher 2003). As Valentine and McKendrick (1997) indicate, safety concerns are limiting the spatial range of children, often restricting play space to areas in the immediate vicinity of the home. Following the Sunday community dinner in Phase II, most of the children retreated to 
another part of the house. In an interview earlier in the day, a resident noted that children's noise had been a concern at shared meals:

During Sunday dinner often the kids would just, it would just get to be really noisy and we now have, like after dinner the kids can go downstairs [next door] and watch a video or whatever. So that keeps the noise under control. (Phase II resident, mother, three children ages 16-23).

While the co-housing model suggested by McCamant and Durrett (1989) and adopted by Dover and Phase II makes space for kids, children's playtime and activity is still managed by parents. A desire to provide a comfortable family environment through the mobilization of an urban-village idyll means, in practice, that the Phase II cohousing development is enclosed from the city proper, with Dover making similar plans for social self-sufficiency. As Mattisson (2002) and Valentine (1997b) note with respect to rural childhood, a life in the countryside can be equally restrictive for youth.

\section{Conclusion}

This paper has attempted to show how individuals who join co-housing groups appropriate city spaces and redevelop them into communities that cater to the needs of families. The results presented in this paper are limited in scope and capture the experience of a small number of parents in Canadian co-housing communities. An inability to interview children directly makes it difficult to fully understand the function and meaning of urban intentional communities to the experience of youth. The findings, however, indicate that alternative housing models and conceptualisations of community can be mobilized to counter parental concerns for the well-being of youth in modern urban centres. Located close to city-centres, cohousing communities allow members easy access to urban amenities and work, while providing a 'village' like environment for children. Contrasting urban danger with the 
relative safety of the co-housing community, parents suggest that the presence of caring adults in co-housing groups mediates the threat posed by teen gangs, traffic, or menacing strangers. Through co-housing parents imagine an urban childhood idyll that replicates some of the safety and freedom more often associated with rural lifestyles (Matthews et al. 2000, Valentine 1996). With multiple families in each development, children can more easily find playmates and limit the need for organized after-school activities. However, the benefits of co-housing communities are perhaps limited to resident children. Functioning with the assumption that community is not easily found in city-centre neighbourhoods and that urban areas are potentially dangerous, groups such as Phase II and Dover are designed to be selfsustaining. The priority of members is to build support networks and friendships within the community. Although Phase II residents interact with neighbours not associated with the co-housing group, they seem to depend for the most part on Phase II members to keep an eye on their children and help in the event of an emergency. Parents' sense of greater safety for their children is a product of carefully managed play and social environments and through controlled entry, equally managed access to surrounding neighbourhoods. Children's increased safety, then, may not extend to surrounding streets, communities or produce a greater sense of safety in the city as a whole.

\section{Acknowledgements:}

Many thanks to Dr. Deborah Leslie for her support and guidance in the completion of this research, and to everyone who has provided helpful feedback for this paper. The detailed comments of the two anonymous reviews are much appreciated.

\section{Notes:}


${ }^{\mathrm{i}}$ As an anonymous reviewer of this paper noted, the wide rage in co-housing community sizes - from a few families to over a hundred households - provides few clues at to the actual function or form of co-housing.

${ }^{\text {ii }}$ Co-housing community names have been changed and all participants are identified through pseudonyms. Considering the relative few number of co-housing developments in Canada, I have withheld town names to ensure participant anonymity.

iii Interviews were completed in 2005 , the value of the properties is approximate and has undoubtedly since changed.

\section{References:}

Canadian Co-housing Network [online]. Available from: http://www.cohousing.ca/index.htm [Accessed 18 May 2009]

Castonguay, G., and Jutras, S., 2009. Children's appreciation of outdoor places in a poor neighbourhood. Journal of Environmental Psychology, 29(1), 101-109.

Christensen, P., and O'Brien, M., 2003. Children in the City: Introducing New Perspectives. In: P. Christensen and M. O'Brien, eds. Children in the City: Home, Neighbourhood and Community. London: RoutledgeFalmer, 1-12.

Christiansen, D.L., 2003. Creating a Life Together: Practical Tools to Grow Ecovillages and Intentional Communities. Gabriola Island, BC: New Society

Cohousing Association of the United States [online]. Available from: http://www.cohousing.org/ [Accessed 18 May 2009].

Fromm, D., 1991. Collaborative Communities: Cohousing, Central Living and Other New Forms of Housing with Shared Facilities. New York: Van Nostrand Reinhold.

Halfacree, K., 2006. From dropping out to leading on? British counter-cultural back-to-theland in a changing rurality. Progress in Human Geography, 30(3), 309-336.

Hallden, G., 2003. Children's Views of Family, Home and House. In: P. Christensen and M. O'Brien, eds. Children in the City: Home, Neighbourhood and Community. London: RoutledgeFalmer, 29-45.

Holloway, S. and Valentine, G., eds., 2000. Children's Geographies: Playing, Living, Learning. London: Routledge

James, A. and James, A., 2004. Constructing Childhood: theory, policy and social practice. Palgrave: New York.

Jones, O., 1997. Little Figures, Big Shadows: Country Childhood Stories. In: P. Cloke and J. Little, eds. Contested Countryside Cultures: Otherness, Marginalisation and Rurality. London: Routledge, 158-179.

Jones, O., 2000. Melting Geography: Purity, Disorder, Childhood and Space. In: S.L. Holloway and G. Valentine, eds. Children's Geographies: Playing, Living, Learning. London: Routledge, 25-40.

Kraftl, P., 2006. Building an idea: the material construction of an ideal childhood. Transactions of the Institute of British Geographers, 31(4), 488-504.

Kraftl, P., 2009. Utopia, childhood and intention. Journal for Cultural Research, 13(1), 6988.

Lucas, T., 1998. Youth Gangs and moral panics in Santa Cruz, California. In:

T. Skelton and G. Valentine, eds. Cool Places: Geographies of Youth

Culture. London: Routledge, 145-160.

Matthews, H., Taylor, M., Sherwood, K., Tucker, F., and Limb, M., 2000. Growingup in the countryside: children and the rural idyll. Journal of Rural Studies, 16 (2), 141-153.

Mitchell, H., Kearns, R.A., and Collins, D.C.A., 2007. Nuances of neighbourhood: Children's perceptions of the space between home and school in Auckland, 
New Zealand. Geoforum, 38(4), 614-627.

Matthews, H., 1987. Gender, home range and environmental cognition. Transactions of the Institute of British Geographers, 12 (1), 43-56.

Mattisson, K.T., 2002. Children's (In)dependent Mobility and Parents' Chauffeuring in the Town and the Countryside. Tijdschrift voor Economische en Sociale Geografie, 93 (4), 443-453.

Maxey, L.J., 2004. The Participation of Younger People within Intentional Communities: Evidence from Two Case Studies. Children's Geographie,s 2 (1), 29-48.

McCamant, K. and Durrett, C., 1989. Cohousing: A Contemporary Approach to Housing Ourselves. Berkeley, CA: Habitat.

McKendrick, J.H., Bradford, M.G., and Fielder, A.V., 2000. Time for a Party!: Making Sense of the Commercialisation of Leisure Space for Children. In: S.L. Holloway and G. Valentine, eds. Children's Geographies: Playing, Living, Learning. London: Routledge, 86-100.

Meijering, L., Huigen, P., and Van Hoven, B., 2007. Intentional communities in rural spaces. Tijdschrift voor Economische en Sociale Geografie, 98(1), 42-52.

Meltzer, G., 1995. The Missing Link: A ‘Sense of Community' and the ESD Debate. In: J. Birkeland, ed. Catalyst'95 - Rethinking the Built Environment, 13-16 July 1995 Canberra. University of Canberra, 70-75.

Meltzer, G., 1999. Cohousing: Linking Communitarianism and Sustainability. Communal Societies: Journal of the Communal Studies Association, 19, 85100.

Meltzer, G., 2001. Cohousing: bringing communalism to...the World? In: P. Foster and G. Meltzer. Proceedings of the Seventh International Communal Studies Conference, 25-27 June 2001 Belzig, Germany. Efal, Israel: International Communal Studies Association, 152-172.

Nayak, A., 2003. 'Through children's eyes': childhood, place and the fear of crime. Geoforum, 34(3), 303-315.

Oswell, D., 1998. A Question of Belonging: television, youth and the domestic. In: T. Skelton and G. Valentine, eds. Cool Places: Geographies of Youth Culture. London: Routledge, 35-49.

Thorleifsdottir, K. (2008). Neighbourhood design: Associations between suburban neighbourhood morphology and children's outdoor, out-of-school, physical activities. Thesis (PhD). North Carolina State University, Raleigh.

Valentine, G., and McKendrick, J., 1997. Children's Outdoor Play: Exploring Parental Concerns About Children's Safety and the Changing Nature of Childhood. Geoforum, 28 (2), 219-235.

Valentine, G., 1996. Angels and Devils: Moral Landscape of Childhood. Environment and Planning D: Society and Space, 1996 (14), 581-599.

Valentine, G., 1997a. 'Oh Yes I Can.' 'Oh No You Can't': Children and Parents' Understanding of Kids' Competence to Negotiated Public Space Safely. Antipode, 29 (1), 65-89.

Valentine, G., 1997b. A Safe Place to Grow Up? Parenting, Perceptions of Children's Safety and the Rural Idyll. Journal of Rural Studies, 13 (2), 137-148.

Veitch, J., Bagley, S., Ball, K., and Salmon, J., 2006. Where do children usually play? A qualitative study of parents' perceptions of influences on children's active free-play. Health \& Place, 12 (4), 383-393.

Watt, P. and Stenson, K., 1998. The street: 'it's a bit dodgy around there' safety, danger, ethnicity and youth people's use of public space. In: T. Skelton and G. Valentine, eds. Cool Places: Geographies of Youth Culture. London: Routledge, 249-265.

Williams, J., 2005. Designing neighbourhoods for social interaction: The case of cohousing. Journal of Urban Design, 10(2), 195-227.

Zeiher, H., 2003. Shaping Daily Life in Urban Environments. In: P. Christensen and 
Pre-print version

M. O'Brien, eds. Children in the City: Home, Neighbourhood and Community. London: RoutledgeFalmer, 66-81. 